\title{
Prahalad's market approach impacting brand loyalty in base of the pyramid Philippines
}

\author{
Marvin O. Bates \\ Department of Marketing, College of Business \\ Lewis University, Romeoville, IL USA \\ Tom A. Buckles \\ Department of Marketing \& Entrepreneurship \\ School of Business \& Management \\ Azusa Pacific University, Azusa, CA USA
}

\section{Keywords}

Brand Loyalty, Base of the Pyramid, BoP, Prahalad, 4As

\begin{abstract}
This purpose of this paper is to examine how Prahalad's 4As market framework influences brand loyalty in the Base of the Pyramid (BoP) market of the Philippines. Specifically, Prahalad's proposed market framework composed of four constructs - awareness, affordability, access, and availability. Prahalad proposed that the 4As strategic framework was a more appropriate alternative to the traditional marketing framework of the 4 Ps - product, price, place and promotion. To date, limited market research has focused on brands and brand loyalty in BoP markets. The present study was conducted first to examine Prahalad's $4 A$ s as a comprehensive set of constructs, and second to measure the impact of the $4 A$ s on brand loyalty in the BoP market of the Philippines.

Using an online survey, data was collected from 606 Philippine college students. Structural equation modeling was utilized to examine the relationship between Prahalad's constructs and their combined impact on brand loyalty. Two constructs, access and availability, were combined into the construct presence, reflecting the consumers' perspective that the product is present in the consumers' marketplace, both in a store and on the shelf. Examining the impact on brand loyalty, both awareness of the branded product and the affordability of the branded product were found to be positively related to brand loyalty; these findings support previous research studies. While presence was not found to be related to brand loyalty, presence was found to be positively related to both awareness and affordability.

The paper concludes with a discussion of how the findings link to previous research, the theoretical implications, recommendations for marketing practitioners, the limitations of this research, and suggestions for future research.
\end{abstract}

Corresponding author: Marvin O. Bates, DBA

Email addresses for corresponding author: BatesMr@lewisu.edu

First submission received: 4th July 2017

Revised submission received: 29 August 2017

Accepted: 30thSeptember 2017

\section{Review of the Problem Statement}

Despite the increase in globalization and the rapid growth in emerging markets, Multinational Corporations (MNC) continue to be challenged in their attempts to penetrate the BoP markets. Prahalad's response to the $\mathrm{MNCs}^{\prime}$ failure to effectively penetrate the BoP markets was a strategic reframing of marketing; Prahalad shifted from the traditional 4Ps' approach to his proposed 4As' strategic marketing approach. Prahalad's $(2004,2010,2012)$ 4As include:

1. Awareness of the product and service so that the BoP consumer knows what is available, and how to use the product or service.

2. Affordability of the product or service for the BoP consumer.

3. Access to the product or service, even for consumers in remote geographical areas.

4. Availability of the product or service with an uninterrupted or continuous supply of the product or service. 
Little research has been undertaken focusing on brands or brand loyalty in BoP markets (Barki \& Parente, 2010; Chikweche \& Fletcher, 2010; Dawar \& Parker, 1994; Tong, 2006). Chikweche and Fletcher found that "research on branding at the BoP is one area where there is a gap in current literature" (2011, p. 248).

While still in its infancy as a field of research, recent studies have begun to focus on brands and brand loyalty in both emerging and BoP markets (Ahmed, Sandhu, Zulkarnain, \& Gulzar, 2011; Eisengerich \& Rubera, 2010; Khan \& Mahmood, 2012; Kim, Forsythe, Gu, \& Moon, 2002; Nguyen, Barrett, \& Miller, 2011; Punniyamoorthy \& Raj, 2007; Wel, Alam, \& Nor, 2011). Surprisingly, none of these nascent studies quantified the basic relationships which exist when considering Prahalad's 4As. Secondly, no studies have quantitatively examined all Prahalad's 4As as a set of independent variables influencing the dependent variable brand loyalty. The purpose of this study was to address these two heretofore unaddressed research questions, specifically:

1. Are Prahalad's 4As unrelated variables, or are they related to each other? And if associations do exist, how strong are the associations?

2. Do the independent variables of Prahalad's 4As effect the dependent variable of brand loyalty? And if effects do exist, how strong are the effects?

Based on these problem statements, research hypotheses for the current study were developed and are presented in Table 1.

\begin{tabular}{ll}
\hline Hypothesis & Hypothesis Statement \\
\hline$H_{1}$ & $\begin{array}{l}\text { No statistically significant relationship exists between awareness and affordability. The } \\
\text { relationship was expected to be neutral. }\end{array}$ \\
\hline$H_{2}$ & $\begin{array}{l}\text { No statistically significant relationship exists between awareness and access. The } \\
\text { relationship was expected to be neutral. }\end{array}$ \\
\hline$H_{3}$ & $\begin{array}{l}\text { No statistically significant relationship exists between awareness and availability. The } \\
\text { relationship was expected to be neutral. }\end{array}$ \\
\hline$H_{4}$ & $\begin{array}{l}\text { No statistically significant relationship exists between affordability and access. The } \\
\text { relationship was expected to be neutral. }\end{array}$ \\
\hline$H_{5}$ & $\begin{array}{l}\text { No statistically significant relationship exists between affordability and availability. The } \\
\text { relationship was expected to be neutral. }\end{array}$ \\
\hline$H_{6}$ & $\begin{array}{l}\text { No statistically significant relationship exists between access and availability. The } \\
\text { relationship was expected to be neutral. }\end{array}$ \\
\hline$H_{7}$ & $\begin{array}{l}\text { Higher levels of product awareness will be positively related to higher levels of brand } \\
\text { loyalty. The relationship was expected to be positive. }\end{array}$ \\
\hline$H_{9}$ & $\begin{array}{l}\text { Higher levels of product } \text { affordability will be positively related to higher levels of brand } \\
\text { loyalty. The relationship was expected to be positive. }\end{array}$ \\
\hline$H_{10}$ & $\begin{array}{l}\text { Higher levels of product } \text { access will be positively related to higher levels of brand loyalty. } \\
\text { The relationship was expected to be positive. }\end{array}$ \\
\hline
\end{tabular}

Table 1: Research Hypotheses

\section{Review of Methodology}

Data collection was accomplished through a survey completed by 1,520 college respondents in the Philippines. Income and family size responses were collected to qualify respondents in the BoP economic level. The final research data set consisted of 606 respondents who were classified as BoP members with an annual income of $135,645 \mathrm{PhP}$ or less (i.e., \$3,000 USD or less). The measurement of Prahalad's 4As constructs was based on Prahalad's definitions. The measurement of the brand loyalty construct was based on an earlier definition by Lam (2007) and Sproles and Kendall (1986). Additional demographic responses were collected to increase homogeneity in the sample, and for potential use in future analysis.

This study included two cross-cultural communication assumptions inherent in international research. The first key assumption was that the questions in the measurement instrument would be understood by Filipino college students. The questionnaire was presented to the respondents in the English language, an official language in the Philippines. Recognizing the existence of cultural language idioms, the measurement instrument was further reviewed for both comprehension and unique language 
issues by five Philippine university professionals. With the completion of this review, the first key assumption was addressed in two ways. First, using English, the survey items would be understood when the questionnaire was deployed in the Philippines. And second, using Philippine English, the measurement instrument would be appropriate for use in the unique environment of the Philippines. The second cross-cultural communication assumption was that the questions in the measurement instrument would be answered accurately and without bias in the Philippines. The measurement instrument was developed to minimize bias-generating questions.

After a thorough pre-analysis data screening, data was analyzed by means of structural equation modelling (SEM). The hypotheses were tested using EQS SEM which can correct for non-normal data in large samples through EQS's use of robust fit statistics (Byrne, 2006).

\section{Discussion and Implications of the Research Results}

Results of the current research are reviewed in this section. First those hypotheses addressing the first research question are reviewed; specifically, "are Prahalad's 4 As unrelated variables, or are they related to each other?" And second, those hypotheses addressing the second research question are reviewed; specifically, "do the independent variables of Prahalad's 4 As effect the dependent variable of brand loyalty"?

\subsection{Relationship among Prahalad's constructs}

Prahalad initially described the 4As as distinct and unrelated constructs; because of this, the null hypothesis structure was utilized to validate the independence of these variables. The hypotheses examined in this section include: $\boldsymbol{H}_{1}, \boldsymbol{H}_{2}, \mathbf{H}_{3}, \boldsymbol{H}_{4}, \boldsymbol{H}_{5}$ and $\boldsymbol{H}_{6}$.

The optimized model identified multiple statistically significant relationships between Prahalad's 4As constructs; these significant relationships are shown in Figure 1. The construct presence is the combined construct made up of three question items initially from the exogenous construct access, and two question items initially from the exogenous construct availability.

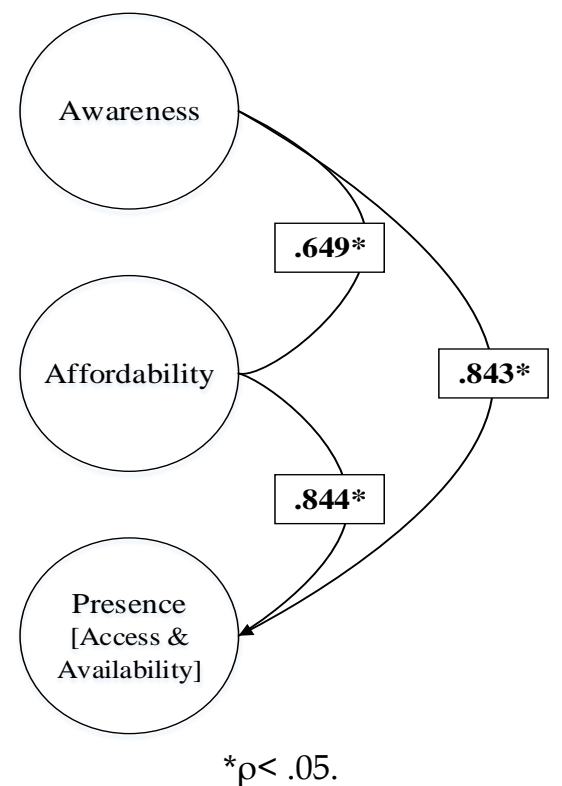

Figure 1: Relationships Among Prahalad's Constructs

$H_{1} \quad$ No statistically significant relationship exists between awareness and affordability. The relationship was expected to be neutral.

This relationship fit the optimized SEM Model. However, the stated hypothesis $\mathbf{H}_{0-1}$ was not supported in this current study; a statistically significant positive estimated correlation was found to exist between awareness and affordability $(r=.649, \mathrm{n}=606, \rho<.05)$.

$\mathrm{H}_{2} \quad$ No statistically significant relationship exists between awareness and access. The relationship was expected to be neutral. 
$\mathrm{H}_{3} \quad$ No statistically significant relationship exists between awareness and availability. The relationship was expected to be neutral.

Prahalad's original constructs access and availability did not fit in the optimized SEM model. Though not eliminated from the optimized model, three items of the construct access were ultimately combined with two items of the construct availability forming the combined construct presence. This combination of the constructs resolved the collinearity that was found to exist between the construct access and the construct availability. Therefore, the stated hypotheses $\boldsymbol{H}_{2}$ and $\boldsymbol{H}_{3}$ were not supported in this current study.

Additionally, a statistically significant positive estimated correlation was found to exist between awareness and presence $(r=.843, \mathrm{n}=606, \rho<.05)$. This provided further evidence that the stated hypotheses $\boldsymbol{H}_{2}$ and $\boldsymbol{H}_{3}$ were not supported in this current study.

$\mathrm{H}_{4} \quad$ No statistically significant relationship exists between affordability and access. The relationship was expected to be neutral.

$\boldsymbol{H}_{5} \quad$ No statistically significant relationship exists between affordability and availability. The relationship was expected to be neutral.

As identified with hypotheses $\boldsymbol{H}_{2}$ and $\boldsymbol{H}_{3}$ Prahalad's original constructs access and availability did not fit in the optimized SEM model. Though not eliminated from the optimized model, three items of the construct access were ultimately combined with two items of the construct availability forming the combined construct presence. In a similar manner, the stated hypotheses $\boldsymbol{H}_{4}$ and $\boldsymbol{H}_{5}$ were not supported in this current study.

Additionally, a statistically significant positive estimated correlation was found to exist between affordability and presence $(r=.844, \mathrm{n}=606, \rho<.05)$. This provided further evidence that the stated hypotheses $\boldsymbol{H}_{4}$ and $\boldsymbol{H}_{5}$ were not supported in this current study.

$\boldsymbol{H}_{6} \quad$ No statistically significant relationship exists between access and availability. The relationship was expected to be neutral.

As discussed, Prahalad's original constructs access and availability did not fit in the optimized SEM model. Therefore, the stated hypothesis $\boldsymbol{H}_{6}$ was not supported in this current study.

\subsection{Summary - Relationship among Prahalad's constructs}

In summary, of the six null hypotheses testing the independence between Prahalad's four constructs, none of them were supported by the findings of this research. Prahalad initially described the 4 As as distinct and unrelated constructs. This quantitative study found no support for the expected independence. On the contrary, this study initially found a degree of collinearity existing between the two constructs of access and availability, which negated the testing of their independence in this study.

Secondly in the optimized SEM model, high positive estimated correlations were found to exist between the construct awareness and affordability $(r=.649)$, awareness and presence $(r=.843)$, and affordability and presence $(r=.844)$.

Based on these findings in this research, the independence of Prahalad's 4As cannot be verified as the 4As consistently showed high levels of positive correlations.

\subsection{Prahalad's constructs impacting Brand Loyalty}

The second research question of this research examined the impact of Prahalad's four constructs as independent variables impacting the dependent variable brand loyalty. These hypotheses examined in this section include: $\boldsymbol{H}_{7}, \boldsymbol{H}_{8}, \boldsymbol{H}_{9}$ and $\boldsymbol{H}_{10}$. As described above the optimized model also identified multiple statistically significant relationships between Prahalad's 4As constructs as independent variables, and the dependent variable brand loyalty; these significant relationships are shown in Figure 2. 


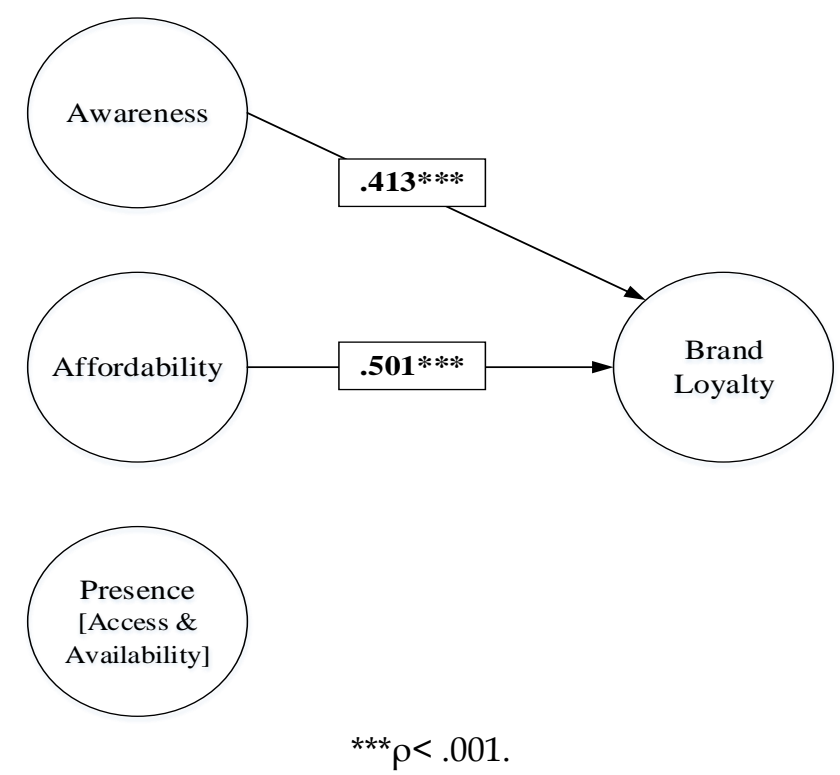

Figure 2: Prahalad's 4As as Independent Variables Impacting the Dependent Variable Brand Loyalty

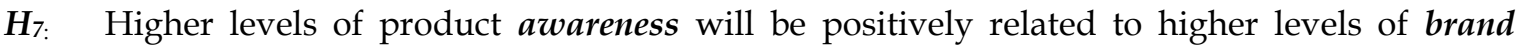
loyalty. The relationship was expected to be positive.

This relationship fit the optimized SEM Model. The stated hypothesis $\boldsymbol{H}_{7}$ was supported in this current study. A statistically significant standardized parameter estimate was found to exist between awareness and brand loyalty $\left(\beta_{\text {standardized }}=.413, \mathrm{n}=606, \rho<.001\right)$.

$\boldsymbol{H}_{8:} \quad$ Higher levels of product affordability will be positively related to higher levels of brand loyalty. The relationship was expected to be positive.

This relationship fit the optimized SEM Model. The stated hypothesis $\boldsymbol{H}_{8}$ was supported in this current study. A statistically significant standardized parameter estimate was found to exist between affordability and brand loyalty $\left(\beta_{\text {standardized }}=.501, \mathrm{n}=606, \rho<.001\right)$.

$\mathrm{H}_{9} \quad$ Higher levels of product access will be positively related to higher levels of brand loyalty. The relationship was expected to be positive.

$H_{10}$ Higher levels of product availability will be positively related to higher levels of brand loyalty. The relationship was expected to be positive.

Prahalad's original constructs access and availability did not fit in the optimized SEM model. Though not eliminated from the optimized model, three items of the construct access were ultimately combined with two items of the construct availability forming the combined construct presence. This combination of the constructs resolved the collinearity that was found to exist between the construct access and the construct availability. Therefore, the stated hypotheses $\mathrm{H}_{9}$ and $\mathbf{H}_{10}$ were not supported in this current study.

\subsection{Summary - Prahalad's constructs impacting Brand Loyalty}

Of the four hypotheses testing Prahalad's 4As as independent factors impacting the dependent factor brand loyalty, two of the hypothesis were supported; specifically: awareness significantly impacted brand loyalty $\left(\beta_{\text {standardized }}=.413, \mathrm{n}=606, \rho<.001\right)$, and affordability significantly impacted brand loyalty $\left(\beta_{\text {standardized }}=.501, \mathrm{n}=606, \rho<.001\right)$.

The two remaining hypotheses were not fully tested due to the collinearity existing between access and availability. 


\section{Relationships of Current Study to Previous Research}

The findings of this study both support and extend the earlier research studies focusing on brands and brand loyalty in emerging and BoP markets. Further, this study builds on the market framework of Prahalad's 4As theory.

An empirical study by Nguyen, Barrett and Miller (2011) examined the shampoo purchasing behavior of female consumers in Thailand and Vietnam, both BoP markets. The authors investigated five constructs: brand loyalty, brand awareness, perceived quality, advertising attitudes, and distribution intensity. First, the authors proposed that distribution intensity, an unstated surrogate measure for Prahalad's access, was positively related to brand awareness; this relationship was found to be significant both in Thailand $(\beta=0.34, \rho<.001)$ and in Vietnam $(\beta=0.25, \rho<.05)$. The current study supports this earlier finding, showing, a statistically significant positive estimated correlation between awareness and presence $(r=.843, \mathrm{n}=606, \rho<.05)$. Second, the authors proposed that brand awareness was positively related to brand loyalty: this relationship was supported in Vietnam $(\beta=0.27, \rho<.001)$ but failed to reach statistical significance in Thailand $(\beta=0.04, \rho<.52)$. The current study supports this proposed relationship, showing a statistically significant standardized parameter estimate between awareness and brand loyalty $\left(\beta_{\text {standardized }}=.413, \mathrm{n}=606, \rho<.001\right)$.

A second empirical study by Khan and Mahmood (2012) examined the relationship between the factors brand loyalty and brand equity among consumers of mineral water in Pakistan. Using SEM, the authors found statistically significant positive correlations between the independent variable brand awareness and the intervening variable brand loyalty $(r=.500, \rho<.000)$. Supporting this earlier finding, the current study found a corresponding statistically significant correlation between awareness and brand loyalty $(r=.843, \mathrm{n}=606, \rho<.05)$. This further validates the relationship between awareness and brand loyalty found in BoP markets.

An exploratory study (Kumar, Sharma, Shah, \& Rajan, 2013) developed a conceptual framework focused on the creation of Profitable Customer Loyalty (PCL) in emerging markets. PCL was described as "customers who exhibit both behavioral and altitudinal loyalty, and provide profits to the firm" (2013, p. 58). One research proposition in this conceptual model was that "product awareness, along with awareness of the benefits of the product offerings, leads to the creation of PCL in emerging economies" (2013, p. 64). The current study provided the empirical validation extending the proposed Kumar et al. model, finding a statistically significant standardized parameter estimate between awareness and brand loyalty $\left(\beta_{\text {standardized }}=.413, \mathrm{n}=606, \rho<.001\right)$.

In summary, the findings of this study support and extend the earlier studies focused on brands and brand loyalty in emerging and BoP markets. Next, the impact on Prahalad's 4As theory will be discussed.

\section{Theoretical Implications}

The findings of this study build on the 4As theory as initially proposed by Prahalad (2004, 2010, 2012). First, none of the early international studies examining brand loyalty quantified the underlying relationships which exist when considering Prahalad's 4As as an inclusive set of four variables. The current study tested for the independence of the 4As, and found a high degree of correlation between Prahalad's four constructs. The findings suggest that these four constructs are related to one another. Although contradictory to Prahalad's theories, this finding suggests the need for further analysis and a systematic evaluation of the relationships among the 4As constructs.

Second, no studies have quantitatively examined all Prahalad's 4As as a set of independent variables influencing the dependent variable brand loyalty. The current study addressed this gap in the research literature through its examination of the simultaneous impact of Prahalad's 4As on brand loyalty. As referenced in the preceding section, it has been shown that several studies found a positive relationship between brand awareness and brand loyalty (Nguyen, Barrett, \& Miller, 2011; Khan \& Mahmood, 2012). The current study validated these earlier studies, finding a statistically significant standardized parameter estimate existing between awareness and brand loyalty $\left(\beta_{\text {standardized }}=.413, \mathrm{n}=606, \rho\right.$ $<$.001). While not identified in prior research, the current study found a statistically significant standardized parameter estimate existing between affordability and brand loyalty $\left(\beta_{\text {standardized }}=.501, \mathrm{n}=606\right.$, 
$\rho<.001)$. These findings directly support Prahalad's initial 4As framework as it relates to awareness and affordability (Prahalad, 2004, 2010, 2012).

Third, the current study found the existence of collinearity between the construct access and the construct availability. This collinearity precluded testing the impact of these two constructs as identified in Prahalad's initial 4As framework (Prahalad, 2004, 2010, 2012). However, an underlying explanation of this collinearity may be found in a recent review of business models focused on poverty alleviation; this review identified the term institutional voids (Casselman, Sama, Horak, Stefanidis, Lu, Gevorkyan, \& Carroll, 2015). Although not specifically defined, companies were shown to respond to institutional voids by adapting their business models to the local market, such as developing "novel distribution approaches that alleviate a lack of supply networks or poor transportation infrastructure" (Casselman et al., 2015, p. 78). The construct access and the construct availability can both be viewed through the lens of an institutional void existing in the BoP market. As a reflection of an institutional void in the distribution channel, access and availability would be expected to be highly related. The current study found a high degree of interrelation between these two constructs. Further, the constructs awareness and affordability could be viewed as consumer characteristics, with awareness reflecting the consumers' knowledge of available products, and affordability reflecting the consumers' ability to purchase products. As such, the current study has identified two dimensions of a model, composed of both institutional factors, and consumer characteristics.

Fourth, this study increases the quantitative body of knowledge surrounding BoP markets. Sheth (2011) has suggested that to successfully introduce branded products and services into BoP markets, traditional marketing theories needed to be validated for applicability in the BoP markets. He identified marketing theories describing brands, brand behavior, brand equity and brand loyalty as particularly important to be validated for use in BoP markets. Further, London et al. (2014) focusing on the enterprise, called for the use of "rigorous qualitative and quantitative data analysis approaches to assess individual enterprises, and to aggregate, compare findings across enterprises" (2014, p. 16). This research effort provided partial validation of Prahalad's theory, specifically for the constructs awareness and affordability.

In summary, the findings of this current study build on the foundation of theory as initially proposed by Prahalad. First, by testing the 4 As for independence. Second, by providing a partial validation of Prahalad's 4As framework specific to awareness and affordability. Third, by conceptualizing the perspective that both institutional factors and consumer characteristics exist in and influence the market. And fourth, by actively and empirically responding to Sheth's request for additional validation of marketing theories in BoP markets.

\section{Recommendations for Marketing Practitioners}

This paper provides a number of directives for those marketing practitioners who are currently engaged in emerging markets and BoP markets, or for those practitioners who are faced with the potential of engaging in those markets in the future. The uniqueness of these markets has been identified, and the challenges inherent in these markets must be addressed to optimize market success.

This study has identified the existence of two strong relationships positively influencing brand loyalty. The first relationship is between awareness and brand loyalty. Prahalad $(2004,2010)$ identified BoP consumers as both brand-conscious and value-conscious, buying aspirational brands, stating "an aspiration to a new and different quality of life is a dream of everyone, including those at the BoP" (2010, p. 38). Marketing practitioners need to focus on establishing and building increasing awareness of their good or service. The messages of the marketing practitioner should focus on the brand, the brand's value, and even the aspirational qualities of the brand. In communicating these messages, the marketing practitioner should utilize the marketing tools most appropriate for the BoP consumer. For example, mass market communication based on the communication channels utilized by the BoP consumer should be employed. In urban areas, this might include television and radio advertisements, and outdoor advertisements such as billboards and wall posters. Brand logos and in-store displays specific to the small mom and pop stores typically found in BoP neighbourhoods might be particularly effective for the BoP shoppers. Additionally, specific segments of the BoP population may have access to the internet, in which case social media marketing may be an appropriate communication channel for that specific segment. 
The second strong relationship identified in this current study is between affordability and brand loyalty. Marketing practitioners need to focus on providing affordable products to the BoP consumer. Prahalad $(2004,2010)$ identified the need for small unit packages for products sold in BoP markets. This small sized packaging is reflected in both single-serving packages, and low-unit packages. This type of packaging has been defined as sachet packaging, becoming the dominant packaging approach in the BoP markets (Mahajan, Banga, \& Gunther, 2006; Singh, Ang, \& Sy-Chango, 2009). Marketing practitioners need to continue to develop affordable sachet packaged products for the BoP market.

While not directly impacting brand loyalty, this current study identified the strong relationship between presence (e.g., the combination of the two constructs of access and availability) and the two constructs of awareness and affordability. Although not tested in this current study, it appears that presence may function as a positive precursor for both awareness and affordability. If this is the case, then marketing practitioners need to simultaneously focus on establishing new distribution channels in the BoP markets, and strengthening their existing distribution channels.

\section{Limitations}

There are several limitations that are identified. The first major limitation is the geographic location where the current research was conducted. The data collection was completed in the Philippines, specifically centralized around Manila, a major urban area. As such, the results of this current study cannot be generalized to include other Asian populations. While there may be similarity to populations in other Asian countries such as Malaysia or Vietnam, the findings of this current research need to be replicated in those countries before generalized statements can be made about those country-specific populations. Further, since this data was collected in major urban areas near the city of Manila, the results cannot be generalized to include rural areas.

The second major limitation is the common demographics of the respondents. The respondents were currently enrolled college students. These students may be a unique segment of the overall Philippine population because of their level of education. Further these students may be a unique segment of the overall Philippine population because of their age; identified as birth year, the respondents had a mode birth year of 1996 (e.g., at the time this study was conducted, approximately 19 years of age). A population of younger respondents may exhibit different behaviors than those behaviors found in middle-aged or senior-aged populations.

The third major limitation is the data collection method employed. A smart phone application was employed, with the survey administered in a digital format. Using this method of data collection, there is a high probability that the respondents were technology savvy, with an awareness and comfort of using the internet. Further, these respondents may have higher than normal brand awareness due to their internet-based exposure to advertisements and product-specific content on the internet.

\section{Suggestions for Future Research}

To build on the foundations of this study, several suggestions for future research are provided.

\subsection{Addressing identified limitations}

Several of these suggestions for future research are directly tied to the previously identified limitations of this current study. First, this study should be replicated in other geographic, countryspecific markets; for example, in other Asian countries such as Malaysia or Vietnam. This would identify quantified differences in other Southeast Asian populations. This study could be replicated in other countries with significant BoP populations to determine if there is a commonality of behaviors existing in a generalized BoP population.

Second, this current study collected data in major urban areas near Manila, with a total metro population of approximately 12 million. Future research should attempt to differentiate between an urban BoP population and a rural BoP population. There is a strong likelihood for urban populations to utilize elements of living in an urban environment to structure their brand preferences and ultimately their brand choices; some of the urban elements could include: a) the proximity to shopping malls which impacts brand awareness and access to products, usually with high levels of product on-shelf availability; $b$ ) the availability of public transportation providing more efficient access to products; c) the plethora of 
urban media such as television, radio, billboards, and other related brand signage which increases brand awareness; and d) the availability of internet and digital technology which increases brand awareness.

Third, this study should be replicated across multiple age categories. As discussed in the previous section, the currently examined population of young college-aged respondents may exhibit different characteristics than other, older age groups.

Fourth, this study could be further extended by examining the effect of different levels of internet usage. One approach would be to examine heavy, medium and light users of the internet. Heavy users might have an increased level of brand awareness based on their higher than average exposure to internet-based brand-focused advertisements. Heavy users of the internet may additionally have a higher perceived level of product access and availability, sharing a common perception that "everything is available on line".

\subsection{Extending the results of the current study}

Two suggestions for future research come from an examination of the results. First, it would be highly informative to replicate the basic analysis completed in this current study, using middle of the pyramid respondents. Specifically, a total of 612 middle of the pyramid respondents were excluded from this current study. Replicating the methodology with these respondents would highlight the differences and similarities existing between the BoP respondents and the middle of the pyramid respondents.

Finally, it might be possible to develop BoP models based on the two major categories of institutional factors and consumer characteristics as discussed above. Models focused on a grouping of institutional factors would be particularly appealing to marketing practitioners who have a degree of control over those institutional factors.

\section{Summary}

This research adds to the foundation of empirical literature on Prahalad's 4As framework in BoP markets. First, this study tested for independence among the 4As as separate constructs. Rather than independence, this study found high positive estimated correlations among the four constructs. This finding was not supportive of Prahalad's 4As market framework.

This current study found a strong positive relationship between the construct awareness and the construct brand loyalty. This finding supported Prahalad's initial 4As framework (Prahalad, 2004, 2010, 2012), and provided corresponding support for this relationship quantified in earlier empirical studies (Khan \& Mahmood, 2012; Nguyen, Barrett \& Miller, 2011).

Two of the four constructs, access and availability, exhibited collinearity; it was suggested that this collinearity reflects an institutional void in the distribution channel (Casselman et al., 2015). Identified as elements of institutional void, access and availability would be expected to exhibit a high degree of interrelation; this current study found a high degree of interrelation between these two constructs.

\section{References}

Ahmed, M., Sandhu, A. R., Zulkarnain, M., \& Gulzar, T. I. (2011). Factors behind the brand loyalty, developing and proposing a conceptual model. Interdisciplinary Journal of Contemporary Research in Business, 3(3), 1217-1229.

Barki, E., \&Parente, J. (2010). Consumer behaviour of the base of the pyramid market in Brazil. Greener Management International, (56), 11.

Byrne, B. M. (2006). Structural equation modeling with EQS: Basic concepts, applications, and programming. New York: Psychology Press.

Casselman, R. M., Sama, L. M., Horak, S., Stefanidis, A., Lu, V., Gevorkyan, A. V., \& Carroll, R. (2015, February). A review of business models, mechanisms and solutions for the alleviation of poverty. In Prosperity, poverty and the purpose of business: Rediscovering integral human development in the Catholic Social Tradition (p. 74-79). Symposium conducted at the 9th International Conference on Catholic Social Thought and Business Education, Manila, Philippines.

Chikweche, T., \& Fletcher, R. (2011). Branding at the base of pyramid: a Zimbabwean perspective. Marketing Intelligence \& Planning, 29(3), 247-263. 
Dawar, N., \& Parker, P. (1994). Marketing universals: Consumers' use of brand name, price, physical appearance, and retailer. Journal of Marketing, 58(2), 81.

Eisingerich, A. B., \& Rubera, G. (2010). Drivers of brand commitment: A cross-national investigation. Journal of International Marketing, 18(2), 64-79.

Khan, M. A., \& Mahmood, Z. (2012). Impact of brand loyalty factors on brand equity. International Journal of Academic Research, 4(1), 33-37.

Kim, J., Forsythe, S., Gu, Q., \& Moon, S. J. (2002). Cross-cultural consumer values, needs and purchase behavior. The Journal of Consumer Marketing, 19(6), 481-

Kumar, V., Sharma, A., Shah, R., \& Rajan, B. (2013). Establishing profitable customer loyalty for multinational companies in the emerging economies: A conceptual framework. Journal of International Marketing, 21(1), 57-80.

Lam, D. (2007). Cultural influence on proneness to brand loyalty. Journal of International Consumer Marketing, 19(3), 7-21.

London, T., Sheth, S., \& Hart, S. L. (2014). A roadmap for the base of the pyramid domain: Re-energizing for the next decade. (No. 1). Ann Arbor, Michigan.

Mahajan, V., Banga, K., \& Gunther, R. (2006). The 86 percent solution: How to succeed in the biggest market opportunity of the next 50 years. Upper Saddle River, NJ: Wharton School Publishing.

Nguyen, T. D., Barrett, N. J., \& Miller, K. E. (2011). Brand loyalty in emerging markets. Marketing Intelligence \& Planning, 29(3), 222-232.

Prahalad, C. K. (2004). The fortune at the bottom of the pyramid: Eradicating poverty through profits. Upper Saddle River, NJ: Wharton School Publishing.

Prahalad, C. K. (2010). The fortune at the bottom of the pyramid: Eradicating poverty through profits (Revised and updated 5th anniversary ed.). New Jersey: Pearson Education.

Prahalad, C. K. (2012). Bottom of the pyramid as a source of breakthrough innovations. Journal of Product Innovation Management, 29(1), 6-12.

Punniyamoorthy, M., \& Raj, M. P. (2007). An empirical model for brand loyalty measurement. Journal of Targeting, Measurement $\mathcal{E}$ Analysis for Marketing, 15(4), 222-233.

Sheth, J. N. (2011). Impact of emerging markets on marketing: Rethinking existing perspectives and practices. Journal of Marketing, 75(4), 166-182.

Singh, R., Ang, R. P., \& Sy-Changco, J. (2009). Buying less, more often: An evaluation of sachet marketing strategy in an emerging market. Marketing Review, 9(1), 3-17.

Sproles, G. B., \& Kendall, E. L. (1986). A methodology for profiling consumers' decision-marking styles. Journal of Consumer Affairs, 20(2), 267.

Tong, X. (2006). Creation of brand equity in the Chinese clothing market. (Ph.D., University of Missouri Columbia). ProQuest Dissertations and Theses, (Currently available). (305307559).

Wel, C. A. B. C., Alam, S. S., \& Nor, S. M. (2011). Factors affecting brand loyalty: An empirical study in Malaysia. Australian Journal of Basic E Applied Sciences, 5(12), 777-783. 